\title{
QUANTITATIVE DESCRIPTION OF THE SUBSTRUCTURE OF HOT-DEFORMED A-286 SUPERALLOY
}

\author{
${ }^{1}$ Kazimierz DUCKI, ${ }^{1}$ Jacek MENDALA, ${ }^{2}$ Lilianna WOJTYNEK \\ ${ }^{1}$ Silesian University of Technology, Katowice, Poland, EU, \\ kazimierz.ducki@polsl.pl, jacek.mendala@polsl.pl \\ ${ }^{2}$ Opole University of Technology, Opole, Poland, EU, I.wojtynek@po.edu.pl
}

https://doi.org/10.37904/metal.2021.4115

\begin{abstract}
The influence of initial soaking and parameters of hot plastic working on the substructure of the A-286 superalloy have been presented. The research was performed on a torsion plastometer in the range of temperature $900-1150{ }^{\circ} \mathrm{C}$, at a strain rates of $0.1 \mathrm{~s}^{-1}$ and $1.0 \mathrm{~s}^{-1}$. The structural inspections were performed on longitudinal microsections taken from plastometric samples after so-called "freezing". The examination of the microstructure was carried out, using transmission electron microscopy (TEM). Direct measurements on the TEM micrographs allowed the calculation of substructural parameters: the mean subgrain area, and the mean dislocation density. An analysis of the examination results of the alloy substructure revealed dynamic recovery, recrystallization and repolygonization, occurring consecutively in the course of hot deformation. A detailed investigations has shown that substructure of alloy is inhomogeneous, consists of dense dislocation walls, subgrains and recrystallized regions.
\end{abstract}

Keywords: A-286 superalloy, hot deformation, TEM, subgrains, dislocation density

\section{INTRODUCTION}

The behavior of metals and alloys during hot plastic working has a complex nature and it varies with the changing of such process parameters as: deformation, strain rate and temperature [1-3]. The high-temperature plastic deformation is coupled with dynamic recovery and recrystallization processes which influencing the microstructure and properties of steels and alloys.

In the recent years, the constitutive equations describing hot plastic deformation processes have started to take into account the so-called internal variables determining the material condition. These variables include substructural parameters such as [4-6]: dislocation density, subgrain size, subgrain misorientation angle, recrystallized volume fraction and stacking fault energy (SFE). Taking those substructure parameters into consideration in calculations should enable the correct modeling of structural phenomena during hot plastic deformation and enhance the technological processes control for the purpose of obtaining the assumed structures of required properties [7-9].

In this work, the influence of initial soaking and parameters of hot plastic working on the subgrain and dislocation structure changes has been examined in a Fe-Ni superalloy of the A-286 type.

\section{MATERIAL AND EXPERIMENTAL PROCEDURE}

The examinations were performed on rolled bars, $16 \mathrm{~mm}$ in diameter, of an austenitic A-286 type superalloy. The chemical composition is given in Table 1. 
Table 1 Chemical composition of the investigated A-286 superalloy

\begin{tabular}{|c|c|c|c|c|c|c|c|c|c|c|c|c|c|c|}
\hline \multicolumn{11}{|c|}{ Content of an element (wt. \%) } \\
\hline $\mathrm{C}$ & $\mathrm{Si}$ & $\mathrm{Mn}$ & $\mathrm{P}$ & $\mathrm{S}$ & $\mathrm{Cr}$ & $\mathrm{Ni}$ & $\mathrm{Mo}$ & $\mathrm{V}$ & $\mathrm{W}$ & $\mathrm{Ti}$ & $\mathrm{Al}$ & $\mathrm{B}$ & $\mathrm{N}$ & $\mathrm{Fe}$ \\
\hline 0.05 & 0.56 & 1.25 & 0.026 & 0.016 & 14.3 & 24.5 & 1.35 & 0.32 & 0.10 & 1.88 & 0.16 & 0.007 & 0.0062 & 55.3 \\
\hline
\end{tabular}

The samples for investigations were made from rolled bars sections which were subjected to preheating, i.e. $1100{ }^{\circ} \mathrm{C} / 2 \mathrm{~h}$ and $1150^{\circ} \mathrm{C} / 2 \mathrm{~h}$ with subsequent cooling in water. Heat treatment of this type corresponds to the soaking parameters of the investigated superalloy before hot plastic processing [10-12]. The research on the alloy deformability was performed in a hot torsion test on a Setaram torsion plastometer 7 MNG. The plastometric tests were performed at constant strain rates of $0.1 \mathrm{~s}^{-1}$ and $1.0 \mathrm{~s}^{-1}$, with a testing temperature in the range $900-1150^{\circ} \mathrm{C}$. The tests were conducted until total fracture of the samples occurred.

Structural inspections were performed on longitudinal microsections taken from the plastically deformed samples after so-called "freezing", i.e. rapid cooling of the samples in water from the deformation temperature. The examination of the microstructure was carried out using transmission electron microscopy (TEM) with a Jeol JEM-100B. Direct measurements on the TEM micrographs allowed the calculation of the structural parameters: the mean subgrain area $\bar{A}\left(\mu \mathrm{m}^{2}\right)$, and the mean dislocation density $\rho\left(\mathrm{m}^{-2}\right)$.

The mean subgrain areas were determined by a planimetric method with the help of a semi-automatic picture analyser of MOP AMO 3 type. The measurements were conducted on the TEM pictures. The analysed microsections of thin foils involved measurements of about 150 subgrains for each sample.

The mean dislocation density was calculated by use of a method based on counting the inter-section points of a network superimposed over the micrograph with dislocation lines. The dislocation density $\rho$ was defined for the thin foils according to the relation given by Klaar et al. [13] and Martin et al. [14]:

$\rho=\frac{x \cdot\left(n_{1} / l_{1}+n_{2} / l_{2}\right)}{t} \quad\left[\mathrm{~m}^{-2}\right]$

where: $x$ - the fraction of invisible dislocations with a Burgers vectors $a / 2<111>$ for the A1 lattice, $I_{1(2)}-$ the total length of the horizontal (vertical) lattice lines, $n_{1(2)}$ - the number of intersections of the horizontal (vertical) lattice lines with dislocations, $t-$ the thickness of foil.

\section{RESULTS AND DISCUSSION}

The A-286 superalloy in its initial state was characterized by an austenitic structure with an insignificant quanity of undisolved precipitates, i.e. $\mathrm{TiC}, \mathrm{Ti}(\mathrm{C}, \mathrm{N}), \mathrm{TiN} \mathrm{Ti}_{4} \mathrm{C}_{2} \mathrm{~S}_{2}, \mathrm{Ni}_{2} \mathrm{Si}$ and $\mathrm{MoB}$ [15]. The mean dislocations density in the supersaturated material amounted to $\rho=4.88 \times 10^{12} \mathrm{~m}^{-2}$ (after $1100^{\circ} \mathrm{C} / 2 \mathrm{~h}$ ) and $\rho=3.99 \times 10^{12} \mathrm{~m}^{-2}$ (after $1150^{\circ} \mathrm{C} / 2 \mathrm{~h}$ ).

The results of the investigations of the alloy substructure after the deformation in a temperature range of 900 $-1050{ }^{\circ} \mathrm{C}$ and a strain rate $0.1 \mathrm{~s}^{-1}$ and $1.0 \mathrm{~s}^{-1}$ are presented in Figures $1-9$. The changes in alloy substructure were similar for both variants of initial soaking and were dependent on deformation temperature and strain rate.

After deformation of samples at $900-950^{\circ} \mathrm{C}$ and a strain rate of $0.1 \mathrm{~s}^{-1}$ and $1.0 \mathrm{~s}^{-1}$ the alloy structure appeared in the advanced stages of a dynamic recovery process (see Figure 1 and Figure 2). In the austenitic regions of high dislocation density a cellular dislocation structure was found togother with subgrains with various densities of dislocations (see Figure 1). In samples deformed at $950{ }^{\circ} \mathrm{C}$ and a rate of $1.0 \mathrm{~s}^{-1}$, nuclei of recrystallized grains were noticed in the subgrain matrix and the deformation microtwings appear (Figure 2).

The alloy deformed within the temperature range of $1000-1050{ }^{\circ} \mathrm{C}$ is characterized by a microstructure typical of a dynamically recrystallized material (see Figure 3 and Figure 4). The austenite microstructure is composed predominantly of recrystallized grains free of dislocations (see Figure 3). Further perfecting of the substructure 
is observed in the neighbouring subgrains, as evidenced by equiaxiality of the subgrains and the decreasing density of dislocations inside them (see Figure 4). It was found that a higher strain rate $\left(1.0 \mathrm{~s}^{-1}\right)$ leads to a growth of the subgrains and a reduction of the dislocation density.

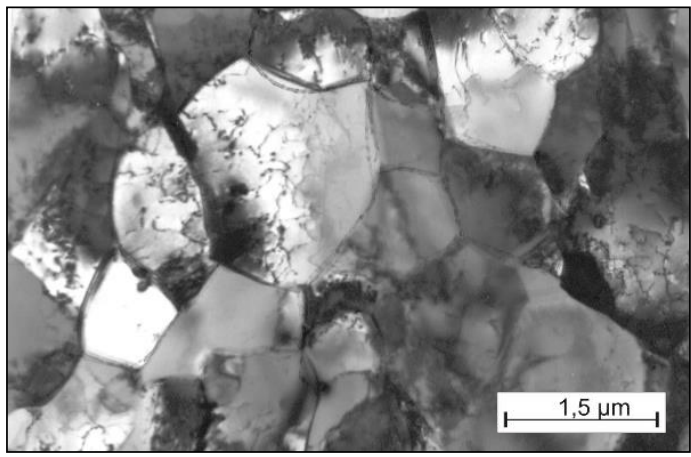

Figure 1 Substructure of the alloy after deformation at $900^{\circ} \mathrm{C} / 0.1 \mathrm{~s}^{-1}$. Celluar dislocations and subgrains and recrystallized grains. Pre-soaking of the alloy: $1100{ }^{\circ} \mathrm{C} / 2 \mathrm{~h}$

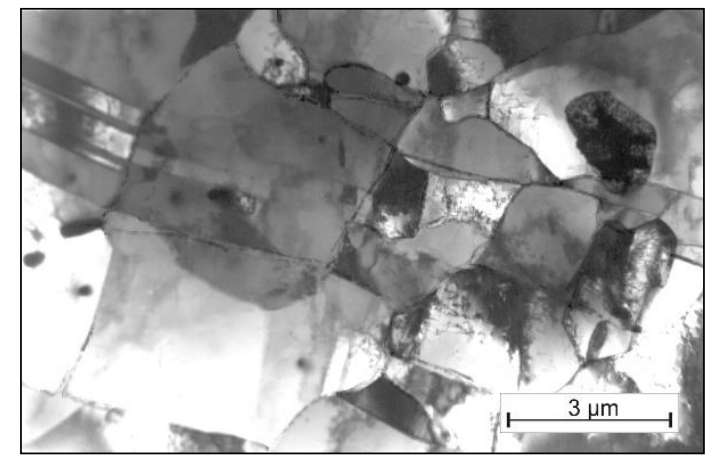

Figure 3 Substructure of the alloy after deformation at $1000{ }^{\circ} \mathrm{C} / 0.1 \mathrm{~s}^{-1}$. Recrystallized grains with twins and

subgrains. Pre-soaking of the alloy: $1100^{\circ} \mathrm{C} / 2 \mathrm{~h}$

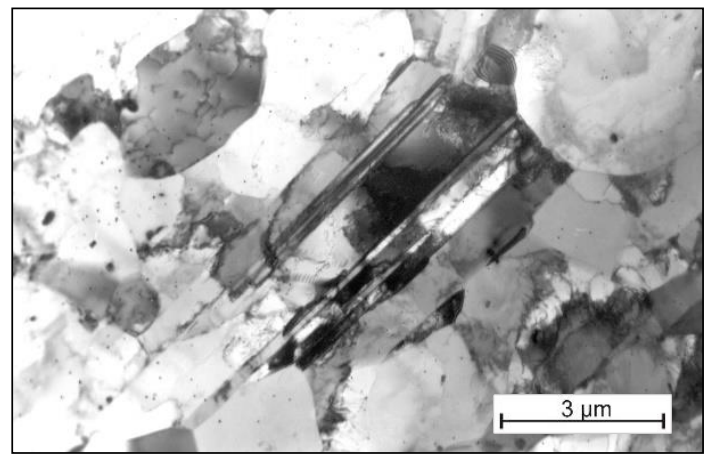

Figure 2 Substructure of the alloy after deformation at $950^{\circ} \mathrm{C} / 1.0 \mathrm{~s}^{-1}$. Subgrains structure and grains with microtwins. Pre-soaking of the alloy: $1150^{\circ} \mathrm{C} / 2 \mathrm{~h}$

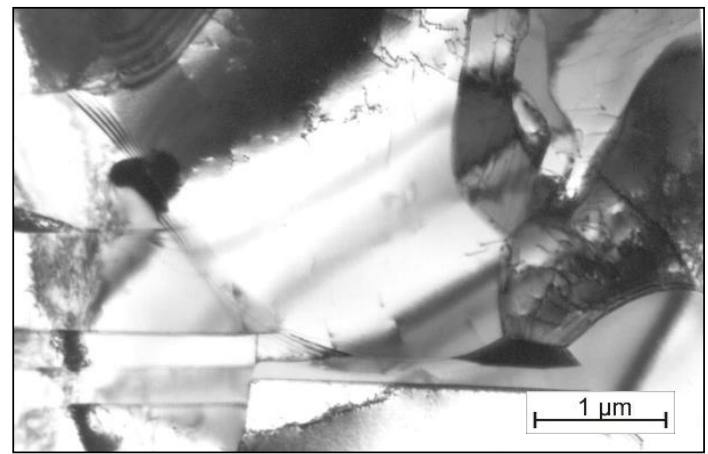

Figure 4 Substructure of the alloy after deformation at $1050^{\circ} \mathrm{C} / 1.0 \mathrm{~s}^{-1}$. The grains after dynamic recrystallization. Pre-soaking of the alloy: $1150{ }^{\circ} \mathrm{C} / 2 \mathrm{~h}$

The growth of new grains in the dynamic recrystallization process proceeded through the coalescence of subgrains and their subsequent growth (see Figure 5). The bending of the grain boundary towards areas with a higher dislocation density indicates the direction of the boundary movement. The principal mechanism of the coalescence includes reactions between dislocations which lead to disappearance of the dislocation boundary and formation of grain from the combination of several neighboring subgrains.

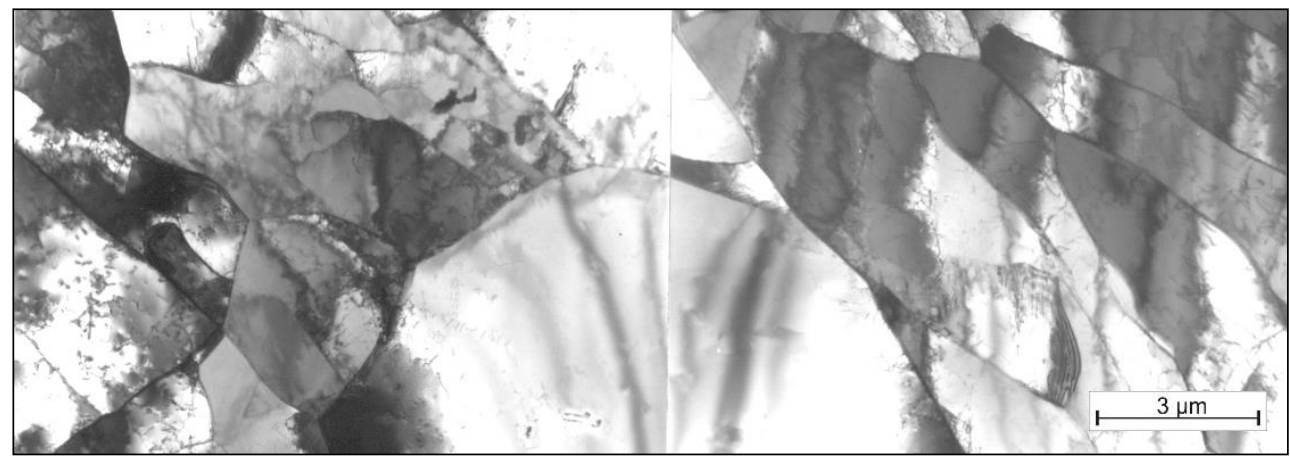

Figure 5 Substructure of the alloy after deformation at $1050^{\circ} \mathrm{C} / 0.1 \mathrm{~s}^{-1}$. The recrystallized grain formation as a result of coalescence of subgrains. Pre-soaking of the alloy: $1150{ }^{\circ} \mathrm{C} / 2 \mathrm{~h}$ 
At the highest deformation temperatures, in the range of $1100-1150{ }^{\circ} \mathrm{C}$, a permanent process of reconstruction was observed in the alloy, named repolygonization (see Figure 6 and Figure 7). It comprised a new regrouping of dislocation with creation of new subgrain boundaries and partions of a polygonal type (see Figure 6). Deformation of the alloy at a higher rate of $1.0 \mathrm{~s}^{-1}$ was accompanied in the substructure by dislocation rearrangement with the formation of polygonal walls and a cellular substructure (see Figure 7).

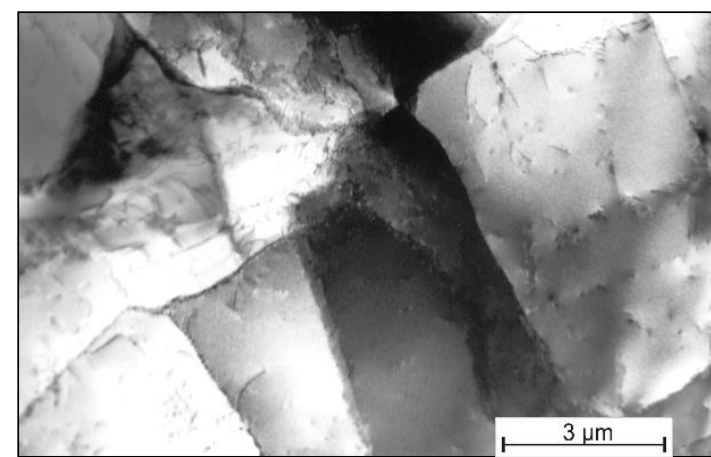

Figure 6 Substructure of the alloy after deformation at $1100{ }^{\circ} \mathrm{C} / 0.1 \mathrm{~s}^{-1}$. The effects of repoligonization in austenite subgrains. Pre-soaking of the alloy: $1100{ }^{\circ} \mathrm{C} / 2 \mathrm{~h}$

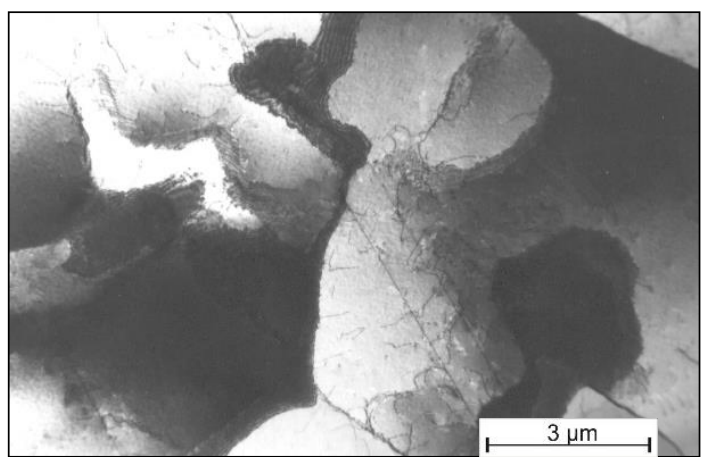

Figure 7 Substructure of the alloy after deformation at $1100^{\circ} \mathrm{C} / 1.0 \mathrm{~s}^{-1}$. Austenite repoligonization and a cellular dislocation structure. Pre-soaking of the alloy: $1150{ }^{\circ} \mathrm{C} / 2 \mathrm{~h}$

The course of changes in mean subgrain sizes depending on the temperature deformation and strain rate for the two variants of initial soaking of the alloy is shown in Figure $\mathbf{8}$ and Figure $\mathbf{9}$. It was found that an increase in the alloy deformation temperature from 900 to $1150^{\circ} \mathrm{C}$ results in a growth of the subgrains.

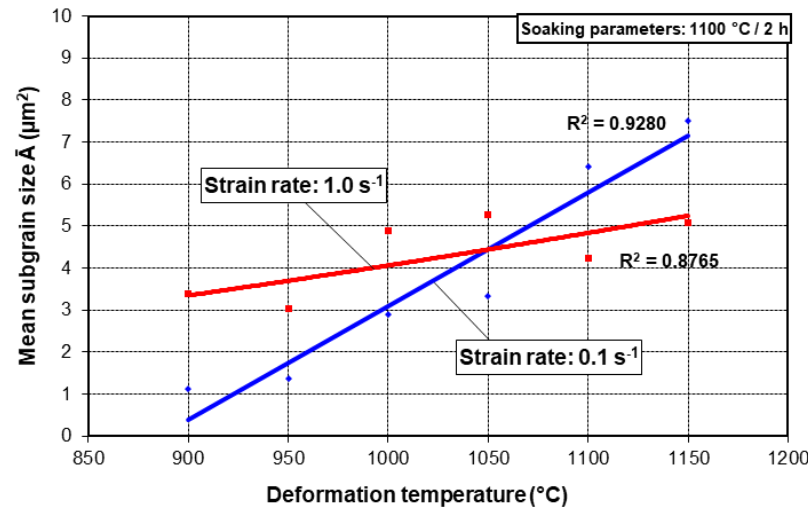

Figure 8 The effect of temperature deformation and strain rate on the mean subgrain size. Pre-soaking of the alloy: $1100{ }^{\circ} \mathrm{C} / 2 \mathrm{~h}$

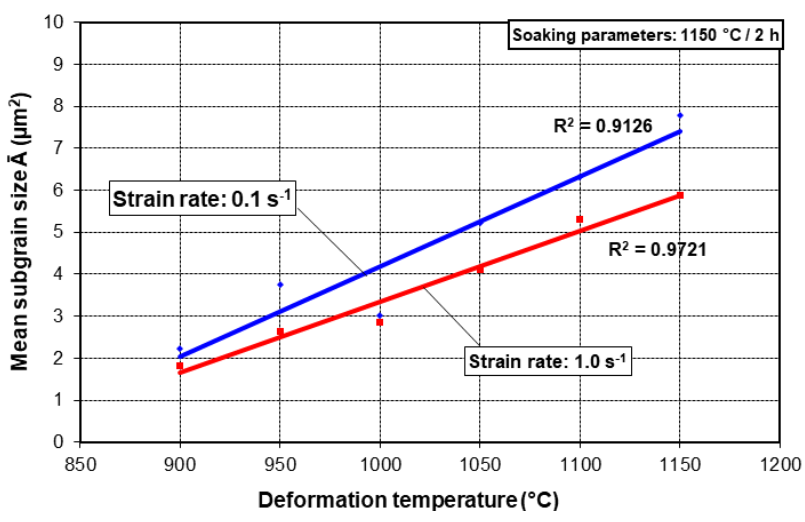

Figure 9 The effect of temperature deformation and strain rate on the mean subgrain size. Pre-soaking of the alloy: $1150^{\circ} \mathrm{C} / 2 \mathrm{~h}$

However, no influence was observed of the conditions of initial soaking on the subgrain size. The mean area of the subgrain plane section $\bar{A}$ varied within the range from $1.0 \mu \mathrm{m}^{2}$ to $7.8 \mu \mathrm{m}^{2}$ for both variants of initial soaking. The influence of the strain rate on the subgrain size was more significant, in particular for the initial soaking at $1100{ }^{\circ} \mathrm{C} / 2 \mathrm{~h}$ (see Figure 8). More intensive changes in the subgrain size were observed at a low strain rate of $0.1 \mathrm{~s}^{-1}$, which can be explained by a higher cumulative deformation in the samples.

The mean dislocation density depending on the deformation temperature and strain rate for the two variants of initial soaking of the alloy is shown in Figure $\mathbf{1 0}$ and Figure 11. An increase of the deformation temperature was accompanied by a decreasing dislocation density. No significant influence was found of the initial soaking parameters on the dislocation density. 


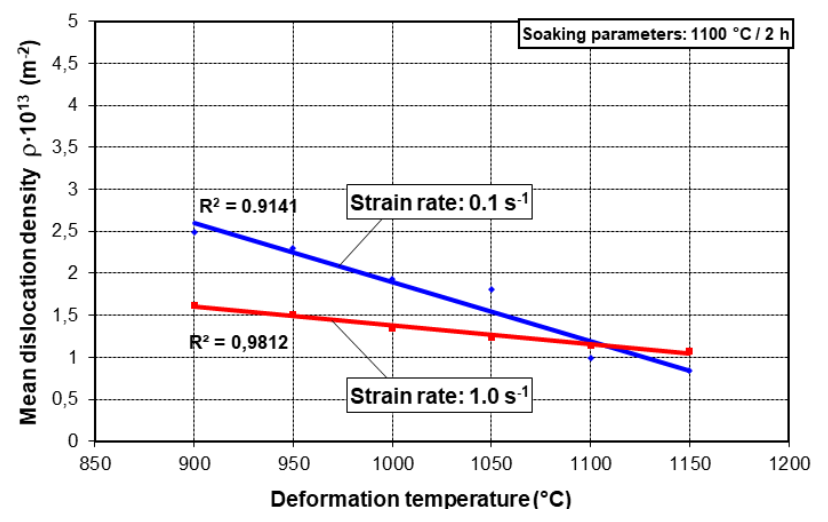

Figure 10 The effect of temperature deformation and strain rate on the mean dislocation density.

Pre-soaking of the alloy: $1100{ }^{\circ} \mathrm{C} / 2 \mathrm{~h}$

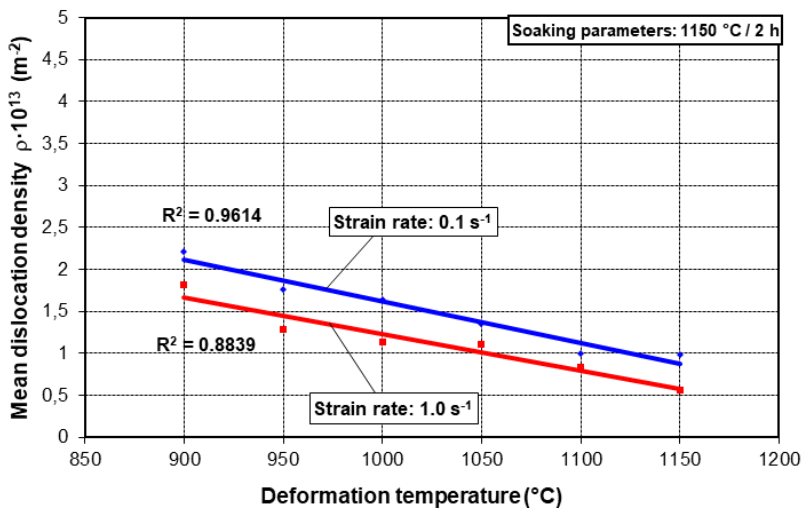

Figure 11 The effect of temperature deformation and strain rate on the mean dislocation density. Pre-soaking of the alloy: $1150{ }^{\circ} \mathrm{C} / 2 \mathrm{~h}$

For both variants of initial soaking, the mean dislocation density varied within narrow range from $0.8 \times 10^{13} \mathrm{~m}^{-2}$ to $2.5 \times 10^{13} \mathrm{~m}^{-2}$. The gradual reduction in the dislocation density observed in the samples as the deformation temperature increased from 900 to $1150{ }^{\circ} \mathrm{C}$ shows a continuous process of substructure reconstruction and redeformation. For both variants of initial soaking of the alloy, higher dislocation densities were obtained for the lower strain rate $\left(0.1 \mathrm{~s}^{-1}\right)$, which can be explained by a higher cumulative deformation in the material.

\section{CONCLUSION}

The investigations into the influence of initial soaking and parameters of hot-working parameters on the substructure of austenitic the A-286 superalloy, revealed the subsequently occurring processes of dynamic recovery, recrystallization and repoligonization. None of discovered stages of alloy substructure transformation constitutes a self-contained process.

A detailed investigations has shown that substructure of alloy is inhomogeneous, consists of dense dislocation walls, subgrains and recrystallized regions. The growth of new grains in the dynamic recrystallization process took place through coalescence of subgrains and their subsequent growth. The phenomenon of repolygonization in the austenite grains was observed at the highest deformation temperature $\left(1100-1150{ }^{\circ} \mathrm{C}\right)$.

The temperature of the process is an essential technological parameter, which has an influence on the size of the subgrains and dislocation density. The increase of the alloy deformation temperature led to a growth of the size of subgrains with a simultaneous decrease of their internal dislocations density. The influence of the strain rate of the alloy on the size of subgrains and dislocation density is complex and depends on the quantity of cumulated deformation in the material.

For both variants of initial soaking of the alloy, the mean size of subgrains $\bar{A}$ increased from $1.0 \mu \mathrm{m}^{2}$ to $7.8 \mu \mathrm{m}^{2}$ as the deformation temperature rose from 900 to $1150^{\circ} \mathrm{C}$. The mean dislocation density $\rho$ decreased gradually in the range from $2.5 \times 10^{13} \mathrm{~m}^{-2}$ to $0.8 \times 10^{13} \mathrm{~m}^{-2}$ as the deformation temperature rose in the range of $900-1150^{\circ} \mathrm{C}$.

\section{REFERENCES}

[1] ZHOU, L.X., BAKER, T.N. Effects of strain rate and temperature on deformation behaviour of IN 718 during high temperature deformation. Materials Science and Engineering. 1994, vol. A177, pp. 1-9.

[2] KOUL, A.K., IMMARIGEON, J.P., WALLACE, W. Microstructural control in Ni-base superalloy. In: Advanced in high temperature structural materials and protective coatings. Ottawa: National Research Council, 1994, pp. 95-125.

[3] SALEHI, A.R., SERAJZADEH, S., YAZDIPOUR, N. A study on flow behaviour of A-286 superalloy during hot deformation. Materials Chemistry and Physics. 2007, vol. 101, pp. 153-157. 
[4] McQUEEN, H.J., RYAN, N.D. Constitutive analysis in hot working. Materials Science and Engineering. 2002, vol. A322, pp. 43-63.

[5] ZHANG, J.M., GAO, Z.Y., ZHUANG, J.Y., ZHONG, Z.Y. Modelling of grain size in superalloy IN 718 during hot deformation. Journal of Materials Processing Technology. 1999, vol. 88, pp. 244-250.

[6] DUCKI, K.J., HETMANCZYK, M., KUC, D. Quantitative Description of the Structure and Substructure of HotDeformed Fe-Ni Austenitic Alloy. Materials Science Forum. 2006, vol. 513, pp. 51-60.

[7] HÄRKEGÅRD, G., GUÉDOU, J.Y. Disc materials for advanced gas turbines. In: Proc. of the $6^{\text {th }}$ Liege Conference: Materials for Advanced Power Engineering. Liege, 1998, pp. 913-931.

[8] SONG, Y.S., LEE, M.R., KIM, J.T. Effect of grain size for the tensile strength and the low cycle fatigue at elevated temperature of alloy 718 cogged by open die forging press. Proceedings of Superalloys 718, 625, 706 and Derivatives 2005. Edited by E.A. Loria, TMS, 2005, pp. 539-549.

[9] CHEN, X.M., LIN, Y.C., CHEN, M.S., LI, H.B., WEN, D.X., ZHANG, J.L., HE, M. Microstructural evolution of a nickelbased superalloys during hot deformation. Materials and Design. 2015, vol. 77, pp. 41-49.

[10] STOLOFF, N.S. Wrought and P/M superalloys. In: ASM Handbook, vol. 1: Properties and selection iron, steels and high-performance alloys. ASM International, USA, 2005, pp. 1478-1527.

[11] PARK, N.K., KIM, I.S., NA, Y.S., YEOM, J.T. Hot forging of a nickel-base superalloy. Journal of Materials Processing Technology. 2001, vol. 111, pp. 98-102.

[12] DUCKI, K., MENDALA, J., WOJTYNEK, L. The characteristic of deformability of Fe-Ni superalloy during hightemperature deformation. In: METAL 2018: 26th International Conference on Metallurgy and Materials. Ostrava: TANGER, 2018, pp. 348-353.

[13] KLAAR, H.J., SCHWAAB, P., ÖSTERLE, W. Round Robin Investigations into the Quantitative Measurement of Dislocation Density in the Electron Microscope. Praktische Metallographie. 1992, vol. 29, pp. 3-26.

[14] MARTIN, U., MÜHLE, U., OETTEL, H. The Quantitative Measurement of Dislocation Density in the Transmission Electron Microscope. Praktische Metallographie. 1995, vol. 32, pp. 467-477.

[15] DUCKI, K.J., MENDALA, J., WOJTYNEK, L. TEM and X-ray examinations of intermetallic phases and carbides precipitation in an Fe-Ni superalloy during prolonged ageing. Solid State Phenomena. 2014, vol. 212, pp. 15-20. 